\title{
АНАЛИТИКО-ОЦЕНОЧНАЯ ДЕЯТЕЛЬНОСТЬ ПЕДАГОГА КАК ФЕНОМЕН СОВРЕМЕННОГО ОБРАЗОВАНИЯ
}

\section{ANALYTICAL AND EVALUATION ACTIVITY OF THE TEACHER AS A PHENOMENON OF MODERN EDUCATION}

\section{N. Gubanova}

Summary: The article is devoted to the phenomenon of analytical and evaluative activity of a teacher. The article identifies the requirements of normative and legislative acts of the Russian Federation in the field of education for the analytical and evaluation activities of pedagogical workers. Special attention is paid to the definition of the functions and components of the analytical and evaluation activity of the teacher. As a research task, the authors tried to assess the degree of teachers understanding of the role of analytical and evaluation activities in improving the quality of education, to determine the level of readiness of teachers to develop analytical and evaluation activities. The article formulates the concept of "analytical and evaluative activity of a teacher", presents the views of researchers on the subject of the essence of the phenomenon of analytical and evaluative activity of a teacher, identifies possible ways of developing analytical and evaluative activity of a teacher, which consist in the development and implementation of an additional professional program to improve the quality of teaching staff in the workplace "Fundamentals of analytical and evaluative activity of a teacher in the context of modernization of education".

Keywords: quality of education; evaluation activity; analytical activity; analytical and evaluation activity of the teacher.

\author{
Губанова Наталья Николаевна \\ заместитель директора по учебно-воспитательной \\ работе, МБОУ Киселевского ГО «Средняя \\ общеобразовательная школа № 30», Кемеровская \\ область-Кузбасс, г. Киселевск \\ gubanovann@bk.ru
}

Аннотация: Статья посвящена феномену аналитико-оценочной деятельности педагога. В статье выявляются требования нормативных и законодательных актов Российской Федерации в сфере образования к аналитико-оценочной деятельности педагогических работников. Особое внимание уделено выявлению функций и компонентов аналитико-оценочной деятельности педагога. В качестве исследовательской задачи выступает попытка оценить степень понимания педагогами роли аналитико-оценочной деятельности в повышении качества образования, определить готовность педагогических работников к развитию собственной аналитико-оценочной деятельности. В статье сформулировано понятие «аналитико-оценочная деятельность педагога», излагаются взгляды исследователей на предмет аналитико-оценочной деятельности педагога, выделяются возможные пути развития аналитико-оценочной деятельности педагога, заключающиеся в разработке и реализации дополнительной профессиональной программы повышения квалификации педагогических работников на рабочем месте «Основы аналитико-оценочной деятельности педагога в условиях модернизации образования».

Ключевые слова: качество образования; оценочная деятельность; аналитическая деятельность; аналитико-оценочная деятельность педагога.

ской Федерации «Развитие образования» является обеспечение соответствия качества российского образования меняющимся запросам населения и перспективным задачам развития российского общества и экономики. Реализация данной цели предусматривает участие образовательных организаций в международных сопоставительных исследованиях качества образования; совершенствования процедур проведения и методик оценки уровня освоения обучающимися образовательных программ; формирования и обеспечения функционирования экспертного сопровождения деятельности системы образования [1].

Понятие «качество образования» в Федеральном законе «Об образовании в Российской Федерации» определено как комплексная характеристика образовательной деятельности и подготовки обучающегося, выражающая степень их соответствия федеральным государственным образовательным стандартам, образовательным стандартам, федеральным государственным требованиям и (или) потребностям физического или 
юридического лица, в интересах которого осуществляется образовательная деятельность, в том числе степень достижения планируемых результатов образовательной программы [2]. Следуя из данного определения, можно констатировать, что контроль качества образования деятельность, направленная на анализ и оценку степени соответствия достижения планируемых результатов обучающихся требованиям федеральных государственных образовательных стандартов.

Аналитико-оценочная деятельность педагога является одной из главных составляющих профессиональной педагогической деятельности, ориентированной на повышение качества современного образования.

Необходимость реализации аналитико-оценочной деятельности в образовательной организации на современном этапе развития образования указана следующих нормативных актах:

— в Федеральном законе от 29. 12. 2012 № 273 Ф3 «Об образовании в Российской Федерации» определены компетенции образовательной организации в осуществлении текущего контроля успеваемости и промежуточной аттестации обучающихся, установлении их форм, периодичности и порядка проведения, а также в проведении самообследования и в обеспечении функционирования внутренней системы оценки качества образования [2];

- в федеральных государственных образовательных стандартах начального общего, основного общего и среднего общего образования установлены требования к результатам освоения обучающимися основной образовательной программы: личностным, метапредметным, предметным [3];

- в профессиональном стандарте «Педагог (педагогическая деятельность в сфере дошкольного, начального общего, основного общего, среднего общего образования) (воспитатель, учитель)» указан перечень требований, определяющих квалификационный уровень необходимых для качественного выполнения трудовых функций педагога, в том числе связанных с аналитико-оценочной деятельностью[4];

- в квалификационных характеристиках должностей работников образования Единого квалификационного справочника должностей руководителей, специалистов и служащих содержатся основные требования, предъявляемые к педагогическому работнику в области аналитико-оценочной деятельности, в частности, обеспечения достижения и подтверждения обучающимися уровней образования (образовательных цензов), оценивания эффективности и результатов обучения по предмету (курсу, программе), учета освоения знаний, овладение умениями, развитие опыта творческой деятельности, познавательного интереса обучающихся [5].
Как видим, действующими нормативными и законодательными актами в сфере образования Российской Федерации прямо указывается на необходимость осуществления аналитико-оценочной деятельности педагога и регулярного оценивания и анализа уровня и качества образовательных результатов обучающихся.

Однако, как показывает практика, педагоги, понимая необходимость повышения качества образования, важным условием которого является осуществление аналитико-оценочной деятельности, имеют недостаточные знания нормативно-правовых аспектов в области профессиональной аналитико-оценочной деятельности, слабо владеют современными методами и средствами оценки и анализа результатов образовательной деятельности. Подтверждением этого являются данные, полученные в результате опроса педагогов на предмет понимания роли АОД в процессе повышения качества образования, готовности к развитию АОД для выполнения требований, предъявляемых существующими нормативными документами в сфере образования.

В опросе было задействовано 134 работника образовательных организаций Киселевского городского округа в возрасте от 20 до 65 лет. Выборка респондентов включала следующие группы: педагогические работники общего образования (82,6 \%), руководители образовательных организаций (12\%), специалисты информационно-методического центра (5,4%). Врезультате опроса были получены следующие сведения.

$96 \%$ опрошенных педагогов осознают значимость АОД для повышения качества образования и признают необходимость в регулярном анализе и оценке информации о состоянии педагогического процесса, более половины педагогов проводят систематический анализ и организуют педагогический процесс на основе полученных аналитических данных.

Многие респонденты (34 \%) отметили, что нуждаются в устранении пробелов в знаниях нормативно-правовых аспектов в области профессиональной аналитико-оценочной деятельности. Вместе с тем педагоги осознают необходимость овладения правовыми знаниями, а также понимают значимость в использовании информационных технологий при осуществлении аналитико-оценочной деятельности.

Все педагоги, участвующие в опросе, отмечают, что регулярно используют педагогический анализ в своей профессиональной деятельности и непосредственно осуществляют следующих видов анализа: анализ выполнения учебных программ, учебного и воспитательного процесса, успеваемости, анализ подготовки к прохождению итоговой аттестации, самоанализ учебных занятий и занятий внеурочной деятельности и другие виды педагогического анализа. 
90 \% респондентов отметили, что владеют методами и средствами контроля, оценки и анализа результатов образовательной деятельности, при этом установлено, что в использовании современных методов оценки и анализа образовательной деятельности часть педагогов испытывает затруднения. Цель контроля, оценивания и аналитической деятельности педагогами в основном сводится к установлению знания/незнания предметов, фактов, явлений; наличия/отсутствия умений; сформированности/несформированности навыков учащихся, в то время как анализ эффективности/малоэффективности используемой системы обучения (и/или педагогической технологии) осуществляется фрагментарно. Выявлено, что выбор оценочных методик и процедур часто осуществляется без применения анализа и учета особенностей образовательной организации, контингента учащихся конкретного класса и индивидуальных профессиональных и личностных особенностей педагога.

Данные проведенного исследования позволяют сделать вывод, что педагоги, указывая на важность и необходимость развития аналитико-оценочной деятельности, испытывают затруднения при ее осуществлении.

Большинство педагогов, прошедших опрос (98 \%), заявили о готовности к развитию АОД с позиции выполнения требований существующих нормативных документов в сфере образования, большинство опрошенных педагогов рассматривают возможности самообразования для развития собственной аналитико-оценочной деятельности в области современных технологий оценивания образовательных результатов и совершенствования педагогической аналитической деятельности.

\section{^итературный обзор}

Вопросы формирования, развития, совершенствования как аналитико-оценочной деятельности педагога в целом, так и отдельных ее составляющих проанализированы в трудах многих ученых.

Вопросы оценки, оценивания, оценочной деятельности являются предметом исследования многих областей науки: в области философии данные проблемы затрагиваются в трудах А.А. Ивина, В.П. Тугаринова, в области педагогической психологии проблемы оценивания Рассмотрены в исследованиях Б.Г. Ананьева, А.А. Бодалева, В.В. Давыдова, Н.А. Курдюковой, А.А. Леонтьева, Л.С. Рубинштейна и других ученых. Педагогические и методические проблемы оценочной деятельности изучали Ш.А. Амонашвили, Л.В.Занков, Г.Ю. Ксензовой, В.М. Полонского, Б.Д. Эльконин и другие авторы.

Вопросам аналитической деятельности педагога посвящены исследования Ю.А. Конаржевского, М.Е. Кондакова, В.П. Панасюка, М.М. Поташника, П.И. Третьякова, В.П. Худоминского, Т.И. Шамовой и других авторов.
Исследованиями анализа и аналитической деятельности в педагогической практике также занимались многие ученые Ю.К. Бабанский, В.И, Загвязинский, Ю.А. Конаржевский, М.М. Поташник, Т.Н. Шамова выделяют анализ как самостоятельную педагогическую функцию. В исследованиях Н.В. Кузьминой аналитическая деятельность рассматривается как гностический компонент в структуре педагогической деятельности, Ю.Н. Кулюткин и другие авторы определяют аналитическую деятельность как вид интеллектуальной деятельности и качество личности педагога, Т.И. Шамова и другие ученые считают аналитическую деятельность структурным компонентом управленческой деятельности.

В.П. Топоровский рассматривает аналитико-оценочную деятельность педагога с точки зрения компетентностного подхода, определяя аналитико-оценочную компетентность педагога как интегральное свойство личности, характеризующее стремление и способность (готовность) педагога реализовать свой потенциал (знания, умения, опыт, личностные качества) для успешной социализации и адаптации в аналитической сфере деятельности [6].

Для более полной характеристики сущности аналитико-оценочной деятельности педагога необходимо уделить внимание таким понятиям как «аналитическая деятельность педагога, педагогический анализ» и «оценочная деятельность педагога, педагогическая оценка».

П.И. Третьяков определяет педагогический анализ как «функцию управления, направленную на изучение фактического состояния дел и обоснованности применения различных способов, средств достижения целей, а также на объективную оценку результатов педагогического процесса и выработку регулирующих механизмов по переводу системы в новое качественное состояние» $[7$, c. 20].

По определению Б.Г. Ананьева педагогическая оценка - это «отметка плюс личное отношение педагога к успехам и неудачам ученика (словесное, эмоциональное, отношение с помощью мимики, жеста, взгляда)» $[8$, c. 7].

А.Н. Субботко определяет оценочную деятельность как систему, включающую в себя целостное единство энергетических, информационных и исполнительных компонентов [9].

Соглашаясь с данными определениями и интерпретируя их, будем понимать под аналитическо-оценочной деятельностью педагога функциональный компонент профессиональной деятельности педагога, основанный на целенаправленной организации и проведении последовательных взаимообусловленных объективных оценочных и аналитических процедур и выработку ре- 
гулирующих механизмов по повышению качества образования.

Основным содержанием аналитико-оценочной деятельности педагога в современном образовании является анализ образовательных результатов в структуре единой системы оценки качества образования (ЕСОКО). Под ЕСОКО понимается совокупность организационных и функциональных структур, обеспечивающая основанную на единой концептуально-методологической базе оценку образовательных достижений граждан, выявление факторов, влияющих на образовательные результаты и получение полного представления о качестве образования, позволяющего анализировать и учитывать влияние различных факторов на результаты работы школ [10].

Рассматривая АОД как феномен современного образования, нельзя не акцентировать внимание на функциях этой деятельности. Очевидно, что структурными компонентами этой деятельности выступают педагогический анализ и педагогическая оценка.

В психолого-педагогической литературе разными авторами выделены различные функции педагогической оценки:

- ориентирующая, стимулирующая, воспитывающая (Б.Г. Ананьев);

- контролирующая (Н.В. Кузьмина);

- образовательная, воспитывающая (В.А. Якунин);

- мотивационная, диагностическая, воспитательная, информационная (А.В. Хуторской);

- образовательная, развивающая, обратной связи (Ш.А. Амонашвили);

- констатирующая, уведомляющая, регулирующая (Г.Ю. Ксензова).

Многие ученые в своих трудах указывают на значительную роль педагогического анализа. В работах Ю.А. Конаржевского [11], М.И. Кондакова [12], Н.С. Сунцова [13], П.И. Третьякова [7] педагогический анализ рассматривается как самостоятельная функция управления, однако, изучив работы этих авторов, мы выделили следующие функции педагогического анализа: информационную, проектировочную, организационную, контрольную, оценочную, корректирующую, управляющую.

Опираясь на данные современной педагогической науки по вопросам аналитической и оценочной деятельности педагогов, а также сопоставив уже выявленные учеными функции педагогической оценки и педагогического анализа, мы определили функции аналитико-оценочной деятельности педагога:

- мотивационно-целевая функция формирует мотивированный подход к определению целей аналитико-оценочной деятельности;

- прогностическая функция предусматривает по- лучение опережающей информации об образовательном процессе для достижения более качественного состояния аналитико-оценочной деятельности;

- контрольно-оценочная функция предусматривает проведение контроля, оценки и анализа результатов образовательной деятельности обучающихся, собственной педагогической деятельности, организация самоконтроля и самооценки обучающихся;

- аналитико-диагностическая устанавливает соответствие полученных данных требованиям федерального государственного образовательного стандарта;

- регулятивно-коррекционная обусловливает выработку рекомендаций по повышению эффективности образовательного процесса на основе анализа данных контроля и оценок;

- информационно-аналитическая действия по сбору, накоплению, обработке, систематизации и анализу информации, служащей основой для выработки оптимальных управленческих решений.

Упрощенно вышеперечисленные функции представлены на рисунке 1

Как и любая деятельность, АОД педагога включает в себя следующие основные этапы, составляющие ее содержание: мотивы, побуждающие субъект к данному виду деятельности; цели, на достижение которых деятельность направлена; средства, с помощью которых деятельность осуществляется; ее результат [14].

Учитывая данные положения и основываясь на исследованиях Ю.А. Конаржевского [11], Е.Г. Матвиевской [15], М.М. Поташника [16] и других ученых, мы определили структуру АОД педагога, содержащую мотивационно-целевой, проетировочный, процессуальный и оценочно-рефлексивный компоненты и представили их в таблице 1.

Итак, на основании анализа психолого-педагогической литературы по изучению феномена аналитико-оценочной деятельности педагога, требований нормативных и законодательных актов Российской Федерации в сфере образования к аналитико-оценочной деятельности педагогических работников, а также в ходе изучения состояния проблемы на практике мы пришли к следующим выводам:

- под аналитическо-оценочной деятельностью педагога понимается функциональный компонент профессиональной деятельности педагога, основанный на целенаправленной организации и проведении последовательных взаимообусловленных объективных оценочных и аналитических процедур и выработку регулирующих механизмов по повышению качества образования; 


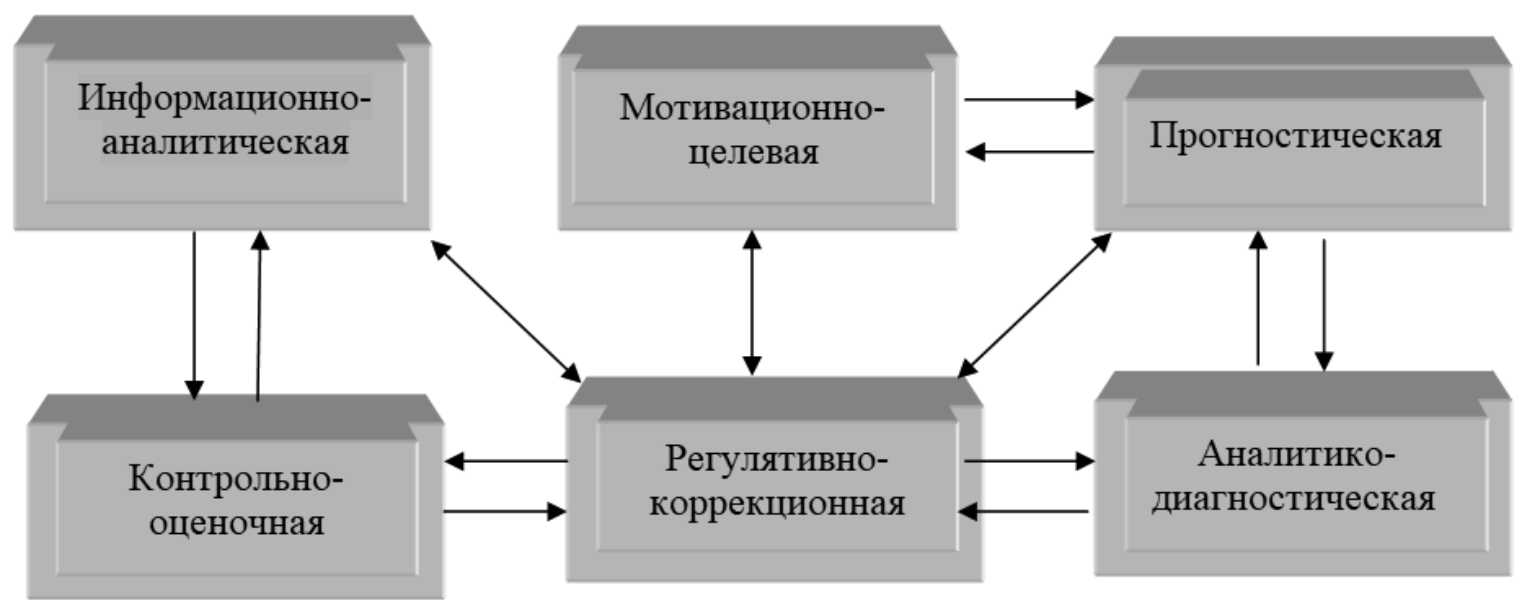

Рис. 1. Функции аналитико-оценочной деятельности пеедагога

Таблица 1.

Компоненты аналитико-оценочной деятельности педагога

\begin{tabular}{|l|l|}
\hline \multicolumn{1}{|c|}{ Компоненты АОД } & \multicolumn{1}{|c|}{ Характеристики компонентов АОД } \\
\hline Мотивационно-целевой & - побуждение познавательной активности педагога на выявление новых тенденций АОД в науке и практике с \\
& учетом его мотивов, интересов; \\
& - целеполагание; \\
& - обеспечение глубины познания информации о состоянии анализируемого объекта (Ю.А. Конаржевский); \\
& - обеспечение соответствия содержания оценочной деятельности содержанию образования (Е.Г. Матвиевская) \\
\hline Проектировочный & - проектирование результатов в сопоставлении с исходными данными; \\
& - анализ имеющихся средств, пригодных для достижения искомого результата; \\
& - конструирование АОД; \\
& - теоретическое осмысление педагогической деятельности \\
\hline Процессуальный & - педагогическая диагностика; \\
& - определение качества знаний, качества управления, качества образования \\
\hline Оценочно-рефлексивный & - анализ деятельности, формулирование новых задач; \\
& - коррекция собственной педагогической деятельности; \\
& - функция управления \\
\hline
\end{tabular}

- анализ проведенного опроса педагогов образовательных организаций Киселевского городского округа на предмет понимания роли АОД в процессе повышения качества образования, готовности к развитию АОД для выполнения требований, предъявляемых существующими нормативными документами в сфере образования, позволяют сделать вывод о необходимость развития аналитико-оценочной деятельности педагогических работников общеобразовательных организаций;

- выявленные в ходе исследования функции и компоненты аналитико-оценочной деятельности педагога послужили ориентиром в поиске возможных путей развития аналитико-оценочной деятельности педагога, заключающихся в разработке и реализации дополнительной профессиональной программы повышения квалификации педагогических работников на рабочем месте «Основы аналитико-оценочной деятельности пе- дагога в условиях модернизации образования». В содержание программы повышения квалификации следует включить разделы по изучению современных нормативно-правовых требований к осуществлению аналитико-оценочной деятельности педагога общеобразовательной организации; по определению теоретических основ аналитикооценочной деятельности педагога и анализу перспективных практик разработки и реализации в общеобразовательных организациях внутренней системы оценки качества образования.

Дальнейшие исследования позволят изучить действенность дополнительной профессиональной программы повышения квалификации педагогических работников на рабочем месте «Основы аналитико-оценочной деятельности педагога в условиях модернизации образования» на развитие АОД педагогических работников. 


\section{ЛИТЕРАТУРА}

1. Постановление Правительства РФ от 26.12.2017 N 1642 «0б утверждении государственной программы Российской Федерации «Развитие образования» [Электронный ресурс] - режим доступа: http://www.consultant.ru/document/cons_doc_LAW_286474/ (дата обращения: 10.01.2021).

2. Федеральный закон «0б образовании в Российской Федерации» [Электронный ресурс] - режим доступа: http://www.consultant.ru/document/cons_doc_ LAW_140174/ (дата обращения 08.01.2021).

3. Федеральные государственные образовательные стандарты [Электронный ресурс] - режим доступа: https://fgos.ru/ (дата 0бращения 08.01.2021).

4. Приказ Министерства труда и социальной защиты РФ от 18 октября 2013 г. N 544н "0б утверждении профессионального стандарта "Педагог (педагогическая деятельность в сфере дошкольного, начального общего, основного общего, среднего общего образования) (воспитатель, учитель)" [Электронный ресурс] - режим доступа: https://base.garant.ru/70535556/ (дата обращения 08.01.2021).

5. Квалификационные характеристики должностей работников образования (Утв. Приказом минздравсоцразвития России 0т 26.08.2010 N 761н) [Электронный ресурс] - режим доступа: https://base.garant.ru/199499/ (дата обращения 29.12. 2020).

6. Топоровский В.П. Проблемы совершенствования аналитико-оценочной деятельности педагогических работников [Электронный ресурс] - режим доступа: https://clck.ru/SxugR(дата обращения 05.01.2021).

7. Третьяков П.И. Управление школой по результатам: Практика педагогического менеджмента [Текст] / П.И. Третьяков. - М.: Новая школа, 1997. - 288 с.

8. Ананьев Б.Г. Психология педагогической оценки [Текст] / Б.Г. Ананьев. - Ленинград: Институт мозга, 1935. - 146 с.

9. Субботко А.Н. Формирование у будущего учителя системы оценочной деятельности [Текст]: дис. ... канд. пед. наук: 13.00.08. - Брянск, 2006. - 170 с.

10. Болотов В.А. 0 построении общероссийской системы оценки качества образования [Электронный ресурс] - режим доступа: https://clck.ru/Sxy23 (дата обращения 03.01.2021).

11. Конаржевский Ю.А. Педагогический анализ учебно-воспитательного процесса как фактор повышения эффективности управления общеобразовательной школой [Текст]: дис. ... доктора педагогических наук: 13.00.01. - Челябинск, 1980. - 507 с.

12. Кондаков М.И. Теоретические основы школоведения [Текст] / М.И. Кондаков. - М.: Педагогика, 1982. - 192 с.

13. Сунцов Н.С. Управление общеобразовательной школой. Вопросы теории и практики [Текст] / Н.С. Сунцов. - М.: Педагогика, 1982. - 144с.

14. Психологический словарь: [Текст] / ред.: В.В. Давыдова, А.В. Запорожца, Б.Ф. Ломова и др. М.: Педагогика, 1983. - 448 с.

15. Матвиевская Е.Г. Формирование культуры оценочной деятельности педагога [Текст] / Е.Г. Матвиевская. - Москва: ВЛАДОС, 2008. - 339 с.

16. Поташник М.М. Управление качеством образования [Электронный ресурс] - режим доступа: https://clck.ru/TRtSM (дата 0бращения 03.01.2021).

(c) Губанова Наталья Николаевна (gubanovann@bk.ru). 